\title{
圧縮性せん断流れの二次不安定性により誘起される縦渦構造*1 Streamwise Vortex Structure Induced by Secondary Instability of Compressible Shear Flow
}

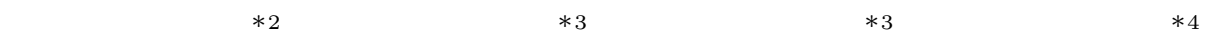 \\ Jun Osaka, Daisuke Noda, Osamu Imamura, Mikiya Araki, \\ 津 江 光 洋*2.河 野 通 方*3 \\ Mitsuhiro Tsue and Michikata Kono
}

Key Words : Streamwise Vortex Structure, Shear Flow, Secondary Instability

\begin{abstract}
Streamwise vortex structure induced by secondary instability of compressible shear flow was numerically investigated. Parallel shear flow with convective Mach number 0.4 was used in the present study. From linear stability analysis, existence of streamwise vortex structure components was confirmed, and scale ratio $\lambda_{z} / \lambda_{x}$ which gives maximum amplification rate was specified. In addition, spatially evolving shear flow was investigated by three-dimensional calculation. Streamwise vortex structure similar to that gotten from linear stability analysis was observed. In the case where white-noise-like disturbance was introduced, growth rate of shear layer was estimated and effect of streamwise vortex structure on growth of shear layer was investigated. Due to streamwise vortex structure induced by secondary instability, growth rate in three-dimensional calculation was larger than the case of two-dimensional case.
\end{abstract}

\section{1. は じめに}

せん断層内に形成される渦構造に関する研究は, 古くは 19 世紀から現在に至るまで盛んに行われてきた . 弚の中で， いち早く超音速せん断層内に形成される大規模渦構造に関 して研究を行ったのは Papamoschou ら ${ }^{1)}$ であった .この 研究を皮切りに, 超音速せん断流机は研究対象として幅広 い注目を集めるに至った .一般に，流れ場の圧縮性が大き くなるにつれ，流れ場に存在する微小変動の成長は抑制さ れることがわかっている ${ }^{1)}$.この事実は，せん断層に形成 される大規模洞構造の成長が抑制され，流体混合が進みに くくなるということを意味する . スクラムジェットエンジ ン燃焼器内の流れ場は, 上記の事実の影響を受ける最も端 的な例である.渦構造の成長が抑制される結果，混合効率 および燃焼効率が低下する．ひいてはエンジン全体の深刻 な性能低下を招いてしまう．この問題を回避するためのさ まざまなデバイスが考案されている ${ }^{2,3)}$. せん断層内に形成 される渦構造の中でも，流れ方向に軸を持つ縦渦は, 上記 のような圧縮性の影響を受けにくいということが過去の研 究により示唆されている.従って, 縦渦構造およびせん断 層の成長に与える影響に関する研究が必要とされている．

一般に, 速い流れと遅い流れが平行に流れるせん断流れ は，流れ方向擾乱に対して不安定である (一次不安定性) 。

\footnotetext{
*1 C) 2005 日本航空宇宙学会

平成 17 年 2 月 22 日原稿受理

*2 東京大学工学系研究科航空宇宙工学専攻

*3 東京大学新領域創成科学研究科

${ }^{* 4}$ 群馬大学工学部機械システム工学科
}

この結果, 流れ場内の流れ方向擾乱が成長して, せん断層 内にはスパン方向渦列が形成される.さらに，スパン方向 渦列を含むせん断流れはスパン方向擾乱に対して不安定で あり，三次元的な縦滑構造が発達することが知られている (二次不安定性). 非圧縮せん断流れにおける，スパン方向 渦および縦渦の代表的な可視化画像 ${ }^{4)}$ を第 1 図に示す.

本研究では, 二次不安定性によって誘起される縦洞構造 に関して，以下の事項を調べることを目的としている．

・圧縮性平行せん断流れ中に形成される縦滑構造 ・縦渦構造がせん断層の成長に及ぼす影響

後者において, 本研究では実用の観点も考慮して, 縦渦の スケールがせん断層の成長に与える影響に対して, 特に焦 点が当てられている.

最初に, 圧縮性せん断流れの不安定性という視点からの 解析結果が示されている. 線形安定性解析 ${ }^{5 \sim 7}$ が乎法とし て用いられた .この方法は,さまざまな擾乱を取り扱える という利点があり, 実験結果とのある程度の整合性も確認 されている1) . スパン方向擾乱の波長を変化させることが できるため，縦渦のスケールがせん断層の成長に及ぼす影 響を調べることが可能である.この反面, 基本流れ場に周 期性が求められる点や，擾乱の初期線形発達段階しか取り 扱うことができない点が次点として挙げられる．

擾乱の非線形発達段階を取り扱うためには, 流れ場の直 接数值計算が必要となる. せん断流れ内に形成される渦構 造を取り扱う場合には, 大きく分けて以下の二つの方法が 挙げられる。

(1) 流れ方向に周期条件を課し，限定された領域内に含まれ 


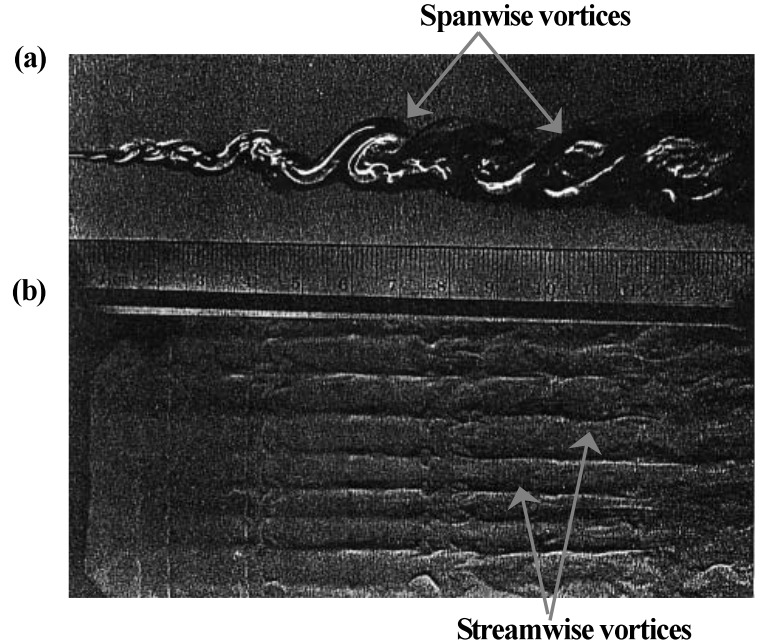

第1図 非圧縮せん断流れにおいて, スパン方向渦および流れ方向渦 が成長する樣子

(a) 側面図 , (b) 俯瞰図 . Bernal ら ${ }^{4)}$ による可視化画像 .

るすべての渦構造の時間的成長を調べる方法 ${ }^{8 \sim 10)}$.

(2) 大規模滑構造のみに注目し, 渦構造の空間的成長を調べ る方法11 13).

三次元渦構造に関する過去の研究では, (1) の方法を採用す ることが多い . (1) の方法は, 散逸スケール程度の微小な渦 構造まで捉えることが可能となる．しかしながら，擾乱の 個数や流れ方向の計算領域か限られるために, 渦構造の成 長が止まってしまうという側面を持つ.ここで, 実験にお いて観察されるせん断流れでは, 無数の擾乱が成長を続け るため, 渦構造の成長は止まらない, (2)の方法では, 成長 し得るすへてての擾乱を捉える限りにおいて，実験において 観察されるような，空間的に成長を続ける渦構造を捉える ことが可能である.上記の点を考慮して，本研究では (2) の 方法を採用した . この計算においても，スパン方向擾乱の 波長を変化させることで, 縦渦のスケールがせん断層の成 長に与える影響が調べられている。

\section{2. 線形安定性解析}

2.1 定式化 本節において，すべての状態量は高速流 の值で無次元化されている . 本研究において取り扱われた 流れ場の概略ならびに座標系を第 2 图に示す．また，本研 究において対象とする流れ場のパラメータを第 1 表に示す. 添え字 1,2 は光れ光れ，高速流および低速流を指す。

本研究では, 以下の二種類の安定性問題が取り扱われて いる.

1. 流れ方向擾乱に対する, 層流せん断流れの安定性問題 (一次不安定性問題)

2. スパン方向擾乱に対する，スパン方向渦列を含むせん 断流れの安定性問題 (二次不安定性問題)

以下では, 線形安定性解析の概略を示す. 解法等の詳細 に関しては, 文献 5)を参照されたい。

すべての状態量は以下の形に表される .

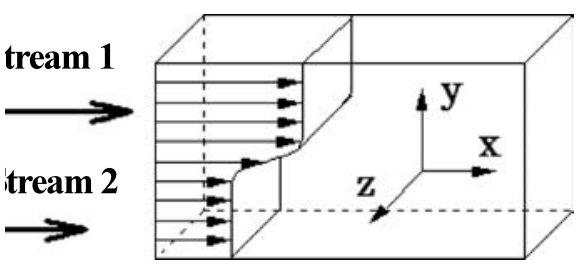

第 2 図 流れ場の概要および座標系

第 1 表 流れ場のパラメータ

\begin{tabular}{ccccc}
\hline$U_{2} / U_{1}$ & $\rho_{2} / \rho_{1}$ & $M_{1}$ & $M_{2}$ & $M_{\mathrm{c}}$ \\
\hline 0.6 & 1.0 & 2.0 & 1.2 & 0.4 \\
\hline
\end{tabular}

$$
\begin{aligned}
& \boldsymbol{f}=\boldsymbol{f}_{\text {basic }}+\boldsymbol{f}^{\prime} \\
& \boldsymbol{f}^{t}=\left[\begin{array}{lllll}
\rho & u & v & w & T
\end{array}\right]
\end{aligned}
$$

一次不安定性問題を取り扱う際には, 基本流れとして, 以 下の流れ方向速度分布が採用された .

$$
U(y)=U_{2}+\frac{\left(1-U_{2}\right)[1+\tanh (y)]}{2}
$$

この速度分布を採用することで, 長さの次元はせん断層渦 度厚さの半値で無次元化されたこととなる. 静温, 静圧は 流れ場において一樣とし, 流れ方向以外の速度成分を持た ないと仮定した．流れ方向に周期性を仮定することにより， 擾乱成分は以下の形に表される .

$$
\boldsymbol{f}_{1 \mathrm{st}}^{\prime}=\hat{\boldsymbol{f}}_{1 \mathrm{st}}(y) \exp \left[i\left(\alpha_{1 \mathrm{st}} x-\omega_{1 \mathrm{st}} t\right)\right]
$$

本研究では, 時間発展モデルが採用された . 波数を実数, 角 周波数を複素数とすることにより，式 (2)，(4) は以下のよ うに変形される .

$$
\boldsymbol{f}_{1 \mathrm{st}}^{\prime}=\hat{\boldsymbol{f}}_{1 \mathrm{st}}(y) \exp \left[i\left(\alpha_{1 \mathrm{st}} x-\omega_{1 \mathrm{st}, \mathrm{R}} t\right)\right] \exp \left(\omega_{1 \mathrm{st}, \mathrm{I}} t\right)
$$

$\omega_{\mathrm{I}}$ は時間増幅率と呼ばれる量であり，流れ場か瀀乱に対し て不安定な場合には正の值をとる .

一次不安定性問題の解として得られる流れ場は, スパン 方向渦列に対応している.従って, 二次不安定性問題では 層流速度分布に，一次不安定性問題より得られた解を重ね 合わせた流れ場を基本流れとして用いた . 基本流れとして , 増幅率が正となる擾乱を用いた場合には，二次不安定性問 題において，解を求めることが困難であった .このため，本 研究では一次不安定性問題における解の中でも, 時間増幅 率がゼロである neutral mode の解を採用した . 以上のこ とを踏まえて，二次不安定性問題における基本流れおよび 擾乱は以下のように表される .

$$
\begin{aligned}
& \boldsymbol{f}_{\text {basic }, \text { nnd }}=\boldsymbol{f}_{\text {laminar }}+\varepsilon \boldsymbol{f}_{1 \text { st,neutral }}^{\prime} \\
& \boldsymbol{f}_{\text {2nd }}^{\prime}=\hat{\boldsymbol{f}}_{\text {2nd }}(x, y) \exp \left[i\left(\alpha_{2 \text { nd }} x+\beta_{2 \text { nd }} z-\omega_{2 \text { nd }} t\right)\right]
\end{aligned}
$$

$\varepsilon$ は 1 より小さい微小量であり, 本研究では, 一次不安定 
性問題における解のうち，流れ方向速度成分の大きさが 高速流の流れ方向速度の $2.5 \%$ になるように $\varepsilon$ の值を設定 した . 過去の非圧縮性せん断流れに関する研究7,10) では, $\alpha_{2 \mathrm{nd}}$ の值によってさまざまなモードに分類される . 本研究 では， $\alpha_{2 \text { nd }}=0$ となるモードのみを対象とした . このモー ドは translative mode と呼ばれており，縦渦の発生機構に 最も関係の深いモードであると言われている .

$x$ 方向には, 対象となる擾乱の一波長分の長さを計算領 域として採用し, $y$ 方向には十分に大きな領域 $(200)$ を採 用した .これらの領域において, $x$ および $y$ 方向格子点数 は乥れ午れ 8 および 100 とした . 二倍密な格子系において 同樣の解析を行い，これらの值が十分な解像度を与えるこ とは確認されている .

2.2 一次不安定性問題 第 3 图には, 一次不安定性問題 における, 流れ方向波数と時間増幅率の関係が示されてい る. $\alpha_{1 \mathrm{st}}=0.400$ において増幅率が最大となり (dominant mode) , $\alpha_{1 \mathrm{st}}=0.916$ において neutral mode を与えるこ とがわかる.第 4 図には, neutral mode の解を基本流れに 重ね合わせた流れ場が示されている.第 4 図では , 擾乱と ともに動く座標系において流れ場が描かれており，明瞭な スパン方向渦が形成されていることがわかる . (a) は渦構 造の中心に対応する平面 (core plane ${ }^{9)}$ ) であり，(b) は鞍 線が存在する平面 (saddle plane ${ }^{10)}$ ) である.この流れ場 が二次不安定性問題における基本流れとして採用された .

2.3 二次不安定性問題 第 5 図には, 二次不安定性問題 における，擾乱スケール比と時間増幅率の関係が示されてい る . スケール比として , スパン方向擾乱の波長と, neutral mode の流れ方向擾乱の波長の比を採用した . 第 5 图から ,

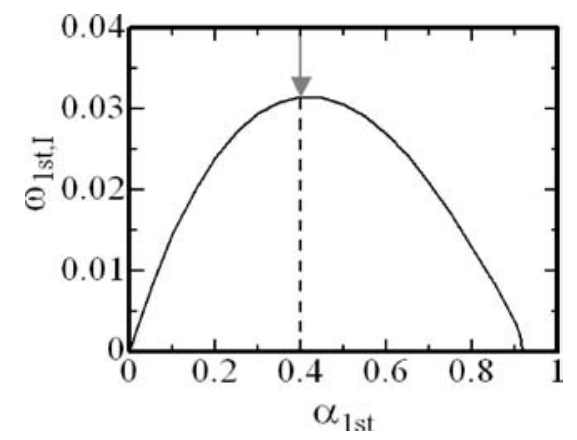

第 3 図 一次不安定性問題における流れ方向波数と時間増幅率の関係

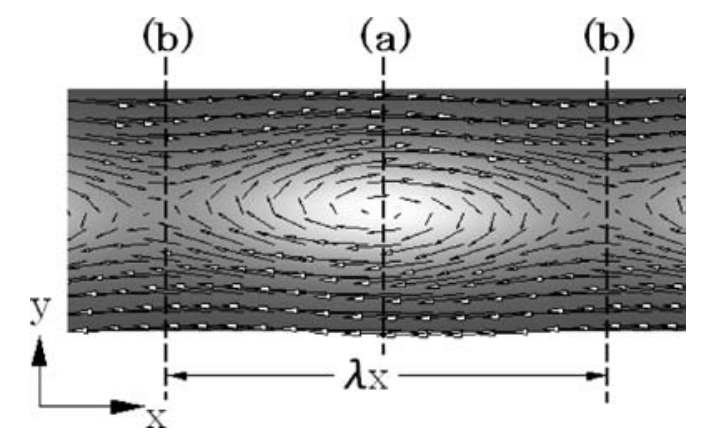

第 4 図 neutral mode の解に対する渦度および速度ベクトル場
増幅率が正となる解が存在することがわかる．従って，ス パン方向渦列を含む流れ場は，スパン方向擾乱に対して不 安定であることがわかる.最大の増幅率を与えるスパン方 向擾乱に対するスケール比は， 0.733 となった . 非圧縮せ ん断流れにおける過去の研究 4,7$)$ では, $2 / 3$ という值が得ら れており，本研究においても，これに近い值が得られたと 言える.第 6 図には， $\beta_{2 \mathrm{nd}}=1.0$ における，流れ場および 渦構造の樣子を示す . 渦構造が存在する領域を明確に示す ために, 第二不変量 ${ }^{14)}$ が正となる領域を示している . $x, z$ 方向に一周期の長さに対応する流れ場が描かれている.重 ね合わせられたスパン方向擾乱によって，基本流れ中に含 まれていだ渦列がスパン方向に変形している樣子がわかる 第 7 図では, $y-z$ 平面におけるスパン方向渦度および速度 ベクトル場が描かれている．渦度の大きな領域が白い領域 として示されている．(a)および (b) に対応する $x$ 位置は， 第 6 図に示されている. (a) は core plane , (b) は saddle plane となっている.これら二つの平面には，縦渦構造が 存在している . 同じ $z$ 位置で比べると, 両平面において, 縦渦の回転方向は逆向きになっていることがわかる . また， 渦度が大きな領域が, 逆向きに変形している樣子もわかる． (a)ではスパン方向渦構造が，(b)では鞍線が光れ光れ，ス パン方向擾乱によって，流れ方向に変形するために，これ らの縦渦構造が出現すると考えられる. 線形安定性解析で は，擾乱の初期発達段階のみを取り扱うため，これまでに 確認された渦構造がどのように成長するかを調べることは 不可能である.より詳細な渦構造を調べるために, 次節に 示されるような数值計算を行った .

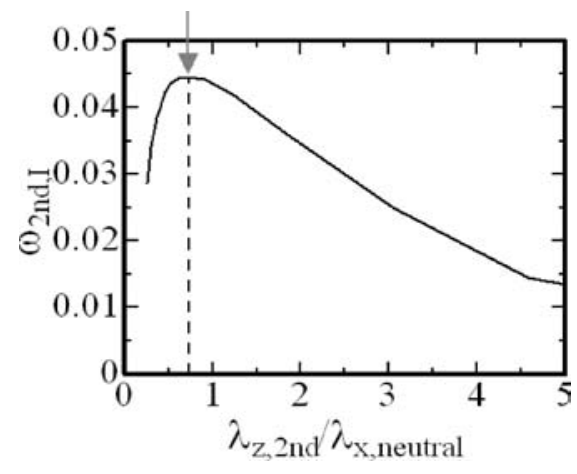

第 5 図 二次不安定性問題におけるスケール比と時間増幅率の関係

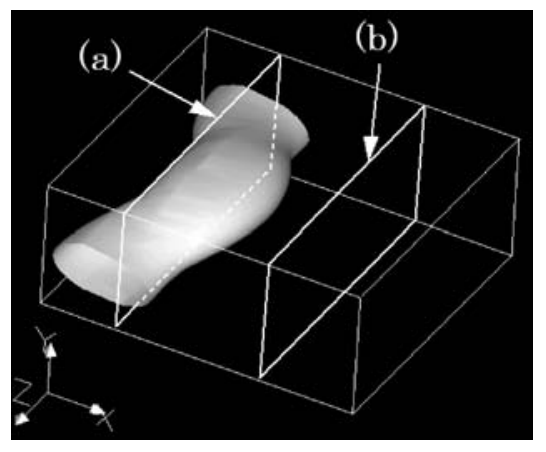

第 6 図 二次不安定性問題における渦構造 
(a)

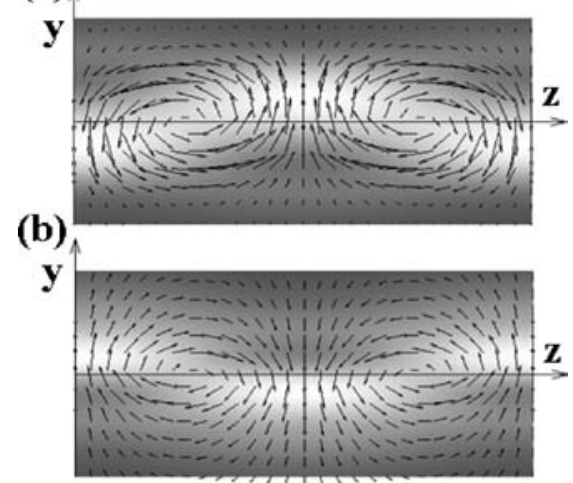

第7図 $y-z$ 平面におけるスパン方向渦度および速度べクトル場

\section{3. 三 次 元 計 算}

3.1 計算方法 対象とする流れ場および座標系は, 一 次不安定性問題において取り扱われた流れ場と同一である。 圧縮性 Navier-Stokes 方程式を支配方程式として採用した。 渦度厚さの半値で見積もられるレイノルズ数は $2.0 \times 10^{4}$ とした . 対流項には基本量に対して 3 次精度 MUSCL 内挿 したSHUS スキーム ${ }^{15)}$ を, 粘性項には 2 次精度の中心差 分を用いた。時間積分には陽解法を採用し，3 階のルンゲ・ クッタ法により，時間精度を 3 次まで確保した . 本研究で は，層流流れ場を対象としているため，擾乱源なしでは渦 構造が成長しない，流入境界において，微小な擾乱成分を 流れ場に導入することにより渦構造を励起した . 擾乱は $y$ 方向速度成分のみに課した 。

Case 1 として, 二次不安定性問題との比較のために, 単 一の流れ方向擾乱のみを含む場合を, Case 2 として, 空 間的に渦構造が成長を続ける場合を光れ光れ取り扱った Case 2 の場合には, 最低限, 増幅し得るすべての擾乱を含 む必要がある.ここで, 一次不安定性問題において得られ た, neutral mode に対応する周波数を持つ擾乱を導入し た二次元計算を別途行い，擾乱がほとんど増幅しないこと を確認した .この結果より, Case 2 では一次不安定性問題 より得られた擾乱を $0<\omega<\omega_{\text {neutral }}$ の範囲において使用 し, Case 1 では代表的な擾乱として, dominant modeを 採用した。

乱れ強さ分布として，ガウシアンが用いられた . 過去の 研究においても, 実験から得られる乱れ強さ分布や, 固有 関数の代わりにガウシアンを用いた例 ${ }^{11,12)}$ があり，いずれ の研究でも, 明確な渦構造を励起することが可能となって いる.三次元的な渦構造を，できる限り計算領域上流で励 起するために, $z$ 方向に対して周期的に変形した乱れ強さ 分布を採用した . 上記のことを踏まえて , 擾乱は以下の式 で表される。

$$
\begin{aligned}
& v^{\prime}(x=0, y, z, t) \\
& \quad=\sum_{i}^{N} \varepsilon_{i} f\left[y-\delta \cos \left(\beta_{z} z\right)\right] \sin \left(-\omega_{i} t+\phi_{i}\right) \\
& \lambda_{z}=2 \pi / \beta_{z}
\end{aligned}
$$

第 2 表 擾乱に関するパラメータ

\begin{tabular}{cccc}
\hline & $\omega_{i}(\mathrm{~N})$ & $\phi_{i}$ & $\varepsilon_{i} \times 10^{2}$ \\
\hline Case 1 & $\omega_{\text {dom }}(1)$ & 0 & 2.5 \\
Case 2 & $0<\omega<\omega_{\text {neutral }}(100)$ & Random & 0.1 \\
\hline
\end{tabular}

第 3 表 $z$ 方向計算領域に関するパラメータ

\begin{tabular}{cccccccc}
\hline$\lambda_{z} / \lambda_{x, \text { dom }}$ & $2 \mathrm{D}$ & 0.5 & 0.75 & 1.0 & 1.5 & 2.0 & 3.0 \\
\hline$\Delta z_{\min }$ & - & 0.14 & 0.21 & 0.27 & 0.27 & 0.27 & 0.27 \\
$N_{z}$ & - & 31 & 31 & 31 & 47 & 61 & 91 \\
Case & 1,2 & 2 & 2 & 1,2 & 2 & 2 & 2 \\
\hline
\end{tabular}

$$
f(y)=\exp \left(-a y^{2}\right)
$$

$\delta=0.5, a=10$ を採用した . (8) から (10) 式に関わる他 のパラメータは第 2 表にまとめられている .

$x, y$ 方向境界には $\mathrm{NSCBC}^{16)}$ を採用した . $z$ 方向には， 乱れ強さ分布に関する変形の半波長のみを計算領域に含め, 対称境界を採用した $. x, y$ 方向には，境界の影響を避け るために十分に大きな計算領域を確保する必要がある。せ ん断層渦度厚さが 2 であることを考えて, 計算領域の大

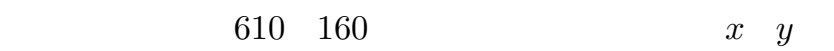

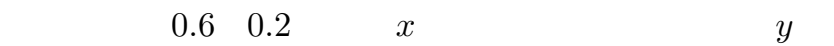
向には $y=0$ から外側に向けて格子幅を次第に増加させ た . Case 1 の場合には， $\lambda_{z}$ の值は dominant mode の波長 $\left(\lambda_{x, \text { dom }}=15.7\right)$ とした . Case 2 の場合には , dominant mode の波長の 0.5 倍から 3.0 倍の場合を取り扱った（計 算領域はこの半値となる).$z$ 方向の計算領域には，等間隔 格子を $N_{z}$ 個配置した . $z$ 方向計算領域に関する，格子系 に関するパラメータは第 3 表にまとめられている .

3.2 二次不安定性により誘起される洞構造 第 8 図に, Case 1 における二次元計算の結果を示す . 以下に示す图で は, 計算開始から過渡状態を経て, 準定常状態に至った後の 流れ場の瞬間図が示されている.せん断流れの一次不安定 性により，流下とともに流入部で加えた擾乱が rollup 過程 を経て成長し，スパン方向渦が形成されている. $x=150$ 付 近から，スパン方向渦の成長が止まり，飽和に至っているこ とがわかる.渦構造はこれ以上成長できないため， $x=150$ 付近よりも下流では, 粘性散逸の効果を受けて渦構造が減 衰していく.第 9 図には，Case 1 における三次元計算の 結果を示す．以下では，流れ場のスパン方向への対称性を 利用して，スパン方向に半波長分だけ折り返すことで，ス パン方向に一周期分の流れ場が描かれている. 第 9 図より， 飽和に至った後，スパン方向渦に絡み付くように成長する， 細い管状をした渦構造 (図中 (1) ) か観察される.この渦構 造により, スパン方向渦は, スパン方向に変形を受けてい る、以下では, スパン方向に変形した渦構造を，「完全に スパン方向に回転軸を持つ」スパン方向渦と区別するため， 「コア」と呼ぶことにする．このような細い管状の渦構造 は，二次元計算では見受けられなかった . 第 9 図 (c) には , 流れ方向渦度の等值面が示されている. 黑と白の領域では，

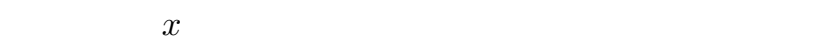
る.第二不変量が正かつ, 流れ方向渦度が存在する領域に, 縦渦構造が存在することとなる。これより，管状の渦構造 


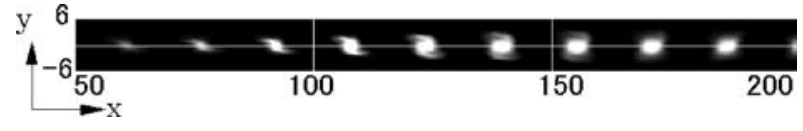

第 8 図 Case 1 における二次元計算結果 (第二不変量)

(a)

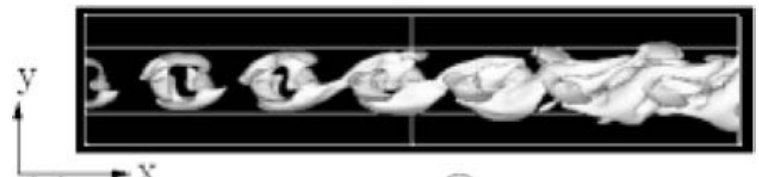

(b)

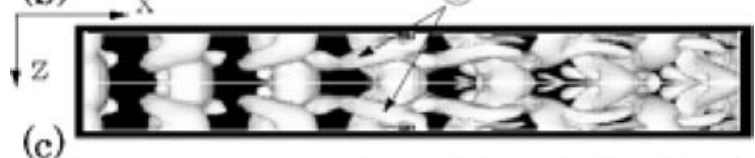

$\lambda_{\mathrm{z}}$

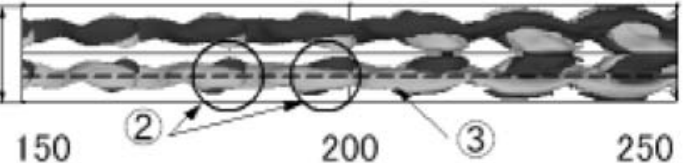

第 9 图 Case 1 における三次元計算結果

(a) 側面図 (第二不変量)，(b) 俯瞰図 (第二不変量)，(c) 俯 瞰図 (流れ方向渦度)
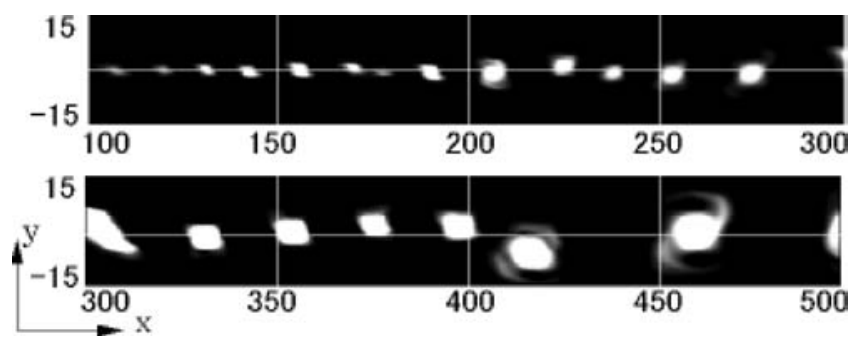

第 10 図 Case 2 における二次元計算結果 (第二不変量)

は縦渦であることがわかる . Rogers らの非圧縮性せん断流 れの DNS ${ }^{9}$ においても，同樣の渦構造が観察されている これより，第 9 図における，コアに絡み付く渦構造は, 非 圧縮性せん断流れ内に成長し得る「リブ構造」と同樣の構 造であると言える .また，第 9 図中の点線部に注目すると， リブ構造 (図中 (3)) は, コア (図中 (2)) とは逆向きの回転 方向を有していることがわかる.上記の事実は, 二次不安 定問題の解として得られた流れ場においても見受けられた 点である.コアおよびリブ構造は光れ光れ，二次不安定性 問題における, neutral mode およびスパン方向擾乱に対応 すると言える. 従って, 本研究において用いた励起方法に よって，流れ場の二次不安定性を励起することが可能であ ることがわかる

第 10 図には, Case 2 における二次元計算の結果を示 す . この場合には，増幅率が正となるすべての擾乱を含む ため，スパン方向渦は飽和に至らず，無限に成長し続ける $x=200$ 付近までは, 一定の波長を持つスパン方向渦構造 が存在している.これは, 成長初期段階では, 最大の増幅 率を持つ擾乱か顕著に成長するためである.このようにし て形成された渦構造のエントレインメント効果により，せ

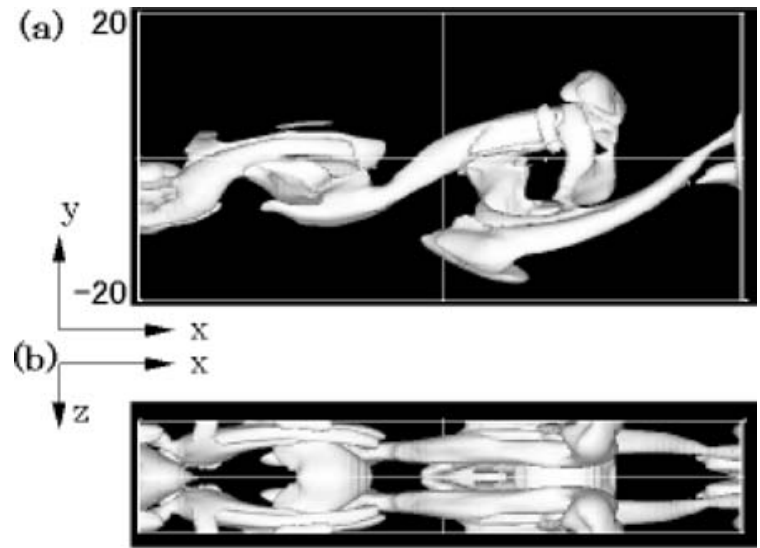

(c)



第11図 Case 2 における三次元計算結果 $\left(\lambda_{z} / \lambda_{x, \text { dom }}=1.0\right)$ (a) 側面図 (第二不変量), (b) 俯瞰図 (第二不変量), (c) 俯瞰図 (第二不変量)。

ん断層のスケールは大きくなる .これに伴い , 低周波の擾 乱が成長しやすくなる $. x=200$ よりも下流では，このよ うな擾乱が成長を始めるため, ペアリングなどの非線形現 象が起こる. 弚の結果, 一見不規則な渦構造が見受けられ るようになる.第 11 図には，Case 2 における三次元計算 の結果の一部を示す .代表的な例として,$\lambda_{z} / \lambda_{x, \mathrm{dom}}=1.0$ の場合のみを示す . Case 1 と同樣に , コアに絡み付くよう に成長するリブ構造が存在することがわかる．また，コア とリブが逆の回転方向を持っているという点も，Case 1 と 共通する点である．これより，渦構造が不規則に成長する ような，現実の流れ場に近い場合においても，流れ場の二 次不安定性により，リブ構造が成長することがわかる．擾 乱のスパン方向波長を 0.5 から 3.0 まで变化させた場合に も，同樣のリブ構造が観察された .

3.3 せん断層の成長に与える影響 リブ構造がせん断層 の成長に及ぼす影響を調べるために,せん断層厚さを算出し た .ここでは，実験において形成されるせん断流れにより近 い Case 2 のみを取り扱うこととする . せん断層厚さの定義 には，ピト一圧分布を利用した . Reyleigh-Pitot の公式か ら算出されたピト一圧を，充分に長い時間平均することによ り，ピト一圧分布を定めた。第 12 図には， $\lambda_{z} / \lambda_{x, \mathrm{dom}}=1.0$ の場合におけるピト一圧等高線を示す．等高線の示す值は， $\mathrm{P}_{+90}$ および $\mathrm{P}_{-90}{ }^{2)}$ である.第 12 図に示すように，三次 元計算の場合には, 縦渦構造によって, せん断層はスパン 方向に変形する . スパン方向にせん断層厚さを平均するこ とによって，三次元計算の場合におけるせん断層厚さを定 義した ${ }^{2)}$. 第 13 図には, Case 2 における , $x$ 方向へのせん 断層厚さの变化を示す . 比較のため, 二次元計算の結果も 示されている.せん断層厚さの振る舞いを考慮して,$x$ 方 向を三つの領域に分類することができる.「(1) $x=0$ から $x=150$ の領域」では, すべての場合において , せん断層厚 


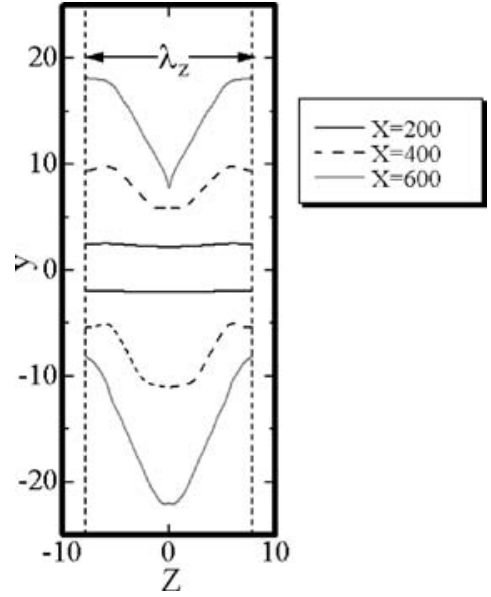

第 12 図 $y-z$ 平面におけるピトー圧の等高線 $\left(\lambda_{z} / \lambda_{x, \mathrm{dom}}=1.0\right)$

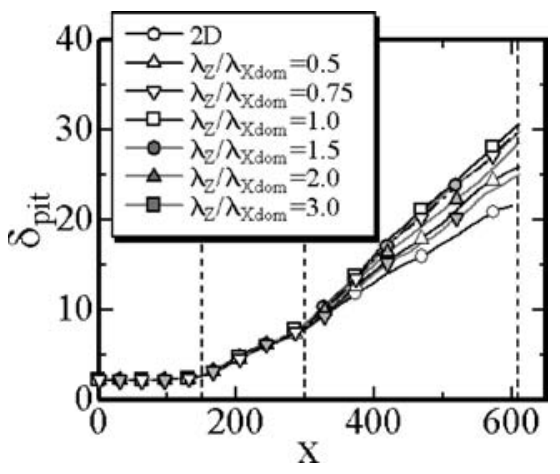

第 13 図 せん断層厚さの $x$ 方向推移

さか湾化しない .この領域では, 入り口境界において導入 された擾乱が , 充分に発達していない . 渦構造によるエン トレイン効果が無いために, この領域ではせん断層厚さが 変化しない.「(2) $x=150$ から $x=300$ の領域」では,流下 とともにせん断層厚さか増加するものの, 全条件での計算 結果において，せん断層厚さにほとんど差が見受けられな い.この領域では, 第 9 図からわかるように, 入り口境界に おいて導入された擾乱のうち, 主に dominant mode が卓 越して滑構造へと成長する. 兴のため, 渦構造によるエン トレインメント効果によってせん断層厚さは増加する . 上 記の Case 1 では, コアが充分に成長し, 飽和に至った後に リブ構造が成長を始めた . 領域 (2) では, dominant mode が成長を続けている領域であるため, リブ構造はまだほと んど成長し始めていない、リブ構造による影響が存在しな いため，領域 (2) では，せん断層厚さに差異が見受けられ ないと考えられる.「(3) $x=300$ よりも下流の領域」にお いては, 弚れ光れの条件における計算において, せん断層 厚さに差異が見受けられる .いずれの三次元計算において も, 二次元計算の場合よりもせん断層厚さは大きくなって いる.これは，第 10 图のように，リブ構造が卓越するた めであると考えられる.特に, $\lambda_{z} / \lambda_{x, \mathrm{dom}}=1.0$ 付近のス ケール比を持つ場合において, せん断層厚さが最も大きく なっていることがわかる .

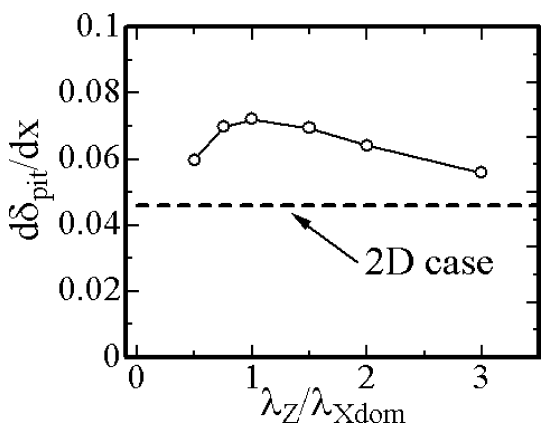

第 14 図 成長率とスケール比の関係

第 14 図には, せん断層の成長率とスケール比の関係を 示す.一般に, せん断層の成長率は, 第 13 図に描かれた グラフの傾きとして表される. 本研究では, リブ構造が成 長率に与える影響を調べるため, 領域 (3) のみにおける成 長率を算出した . 最小自乗法により定められた直線の傾き が成長率として与えられる．第 14 図より，いずれの三次 元計算においても，二次元計算よりも大きな成長率が得ら れていることがわかる. 特に, スケール比が 1 付近となる 場合に成長率は最大となり，二次元計算に比べて $57 \%$ の増 加か認められる . 前章の二次不安定性問題では, 最大の増 幅率を与えるスパン方向擾乱に対するスケール比は 0.733 付近であった . 両者は比較的良好な一致を示している .こ こで，この相違を生んだ原因として，以下のことが考えら れる、線形安定性解析では, 基本流れに含まれる流れ方向 擾乱として一種類の擾乱 (neutral mode) しか含まなかっ た .これに対して，三次元計算では，増幅率が正となるす べての擾乱を含んでおり， pairing などの非線形成長の影響 を受ける .このような擾乱の成長過程に関する相違が，第 一の原因として考えられる．また，三次元計算では，下流 に行くにつれて，卓越するコアの波長が次第に大きくなる． 一方, 線形安定性解析では, 流れ方向擾乱の波長は一定と なっている . スケール比の定義に関する相違が第二の原因 として考えられる

3.4 格子解像度 最後に, 格子解像度の是非について 議論することとする．三方向に二倍の格子密度を設ける場 合，計算機の容量を超えてしまう．乥こで, $x, y$ 方向に二 倍の格子密度を設けた二次元計算, $z$ 方向のみに二倍の格 子密度を設けた三次元計算 $\left(\lambda_{z} / \lambda_{x, \mathrm{dom}}=1.0\right.$ の場合のみ) を行った . 第 15 図には, せん断層厚さの $x$ 方向推移を示


いことがわかる.これより, 本研究で用いた格子系は, 大 規模な゙洞構造を捉えるために, 充分な解像度を有している ことがわかる.

\section{4. 結 論}

本研究では, 圧縮性せん断流れの二次不安定性により誘 起される縦渦構造を調べた . 手法として, 線形安定性解析 および三次元計算が用いられた . 弚の結果として得られた 結論は, 以下のようにまとめられる . 


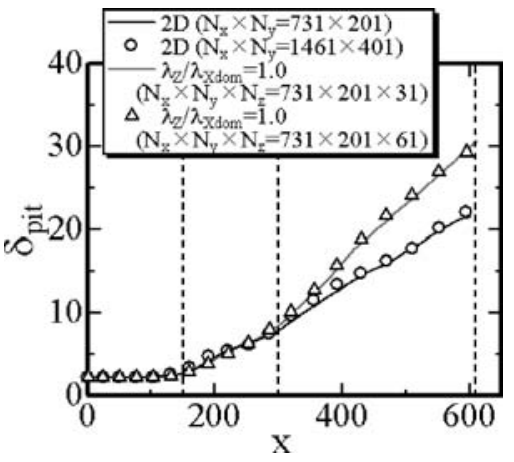

第 15 図 せん断層厚さを用いた格子解像度の確認

・二次不安定性問題において, コアおよびサドル部に観察 された縦洞対の回転方向は逆向きとなった .

・款不安定性問題において, 最大の増幅率を与えるスパ ン方向擾乱のスケール比は， 0.733 付近の値となった .

・ 三次元計算において用いられた励起方法によって，流れ 場の二次不安定性を励起することができた .

・三次元計算において，流れ場の二次不安定性によって励 起された縦渦構造の非線形発達を捉えることができた .

・三次元計算において, 縦渦構造の影響により, せん断層 厚さおよび成長率は二次元計算の場合に比べて増加した .

・ 三次元計算において, 最大の成長率を与えるスケール比 は 1.0 付近の値となった .

\section{参 考 文 献}

1) Papamoschou, D. and Roshko, A.: The Compressible Turbulent Shear Layer: An Experimental Study, J. Fluid Mech., 197 (1988), pp. 453-457.

2) Araki, M., Osaka, J., Tsue, M. and Kono, M.: Effects of Secondary Instability on Mixing in a Compressible Mixing Layer, Proc. 16th ISABE, 2003, CD-ROM.
3) Island, T. C., Urban, W. D. and Mungal, M. G.: Mixing Enhancement in Compressible Shear Layers via Sub-Boundary Layer Disturbances, Phys. Fluids, 10 (1998), pp. 1008-1020.

4) Bernal, L. P. and Roshko, A.: Streamwise Vortex Structure in Plane Mixing Layers, J. Fluid Mech., 170 (1986), pp. 499525.

5) Araki, M., Osaka, J., Nakaya, S., Oshita, M., Tsue, M. and Kono, M.: A Study on Three-Dimensional Disturbances in a Compressible Shear Layer, JSME Int. J. B, 45 (2002), pp. 91-96.

6) Sandham, N. D. and Reynolds, W. C.: Compressible Mixing Layer: Linear Theory and Direct Simulation, AIAA J., 28 (1900), pp. 618-624.

7) Pierrehumbert, R. T. and Windnall, S. E.: The Two- and Three-Dimensional Instabilities of a Spatially Periodic Shear Layer, J. Fluid Mech., 114 (1982), pp. 59-82.

8) Sandham, N. D. and Reynolds, W. C.: Three-Dimensional Simulations of Large Eddies in the Compressible Mixing Layer, J. Fluid Mech., 224 (1991), pp. 133-158.

9) Rogers, M. M. and Moser, R. D.: The Three-Dimensional Evolution of a Plane Mixing Layer: The Kelvin-Helmholtz Rollup, J. Fluid Mech., 243 (1992), pp. 183-226.

10) Schoppa, W., Hussain, F. and Metcalfe, R. W.: A New Mechanism of Small-Scale Transition in a Plane Mixing Layer: Core Dynamics of Spanwise Vortices, J. Fluid Mech., 298 (1995), pp. 23-80.

11) Gathmann, R. J., Si-Ameur, M. and Mathey, F.: Numerical Simulation of Three-Dimensional Natural Transition in the Compressible Confined Shear Layer, Phys. Fluids, 5 (1993), pp. 2946-2968.

12) Li, Q. and Fu, S.: Numerical Simulation of High-Speed Planar Mixing Layer, Comput. Fluids, 32 (2003), pp. 1357-1377.

13) Oh, C. K. and Loth, E.: Unstructured Grid Simulations of Spatially Evolving Shear Layers, AIAA J., 33 (1995), pp. $1229-1238$.

14) Jeong, J. and Hussain, F.: On the Identification of a Vortex, J. Fluid Mech., 285 (1995), pp. 69-94.

15）嶋 英志, 城之内忠正：一粒子的風上法について，日本航空宇宙 学会第 25 期年会講演会講演集, 1994, pp. 36-37.

16) Poinsot, T. J. and Lele, S. K.: Boundary Condition for Direct Simulations of Compressible Viscous Flows, J. Comput. Phys., 101 (1992), pp. 104-129. 